\title{
A avaliação do ensino semipresencial sob à ótica do acadêmico de enfermagem
}

The evaluation of semi-presential teaching from the perspective of the nursing student

La evaluación de la enseñanza semipresencial desde la perspectiva del estudiante de enfermeira

Maria Ana Leticia da Silva ${ }^{1^{*}}$, Stéphanye Venancio Silva ${ }^{1}$, Júlio César Bernardino da Silva ${ }^{1}$, Wanessa Barros da Silva ${ }^{1}$, Maria Willyanne Carneiro de Lucena Santos ${ }^{1}$, Samira Maria Almeida Mota $^{1}$, Maria Valéria Gorayeb de Carvalho ${ }^{1}$, Vanessa Juvino de Sousa ${ }^{1,2}$.

\section{RESUMO}

Objetivo: Avaliar o ensino semipresencial no curso de Bacharelado em Enfermagem sob a ótica dos discentes. Métodos: Trata-se de um estudo transversal, descritivo e explicativo, de abordagem quantitativa com 134 alunos do Centro Universitário Tabosa de Almeida (ASCES-UNITA), em uma cidade pernambucana. Os dados foram analisados por estatística descritiva com análise de tendência central, neste caso a média e o desvio padrão. O projeto de pesquisa foi aprovado pelo Comitê de Ética. Resultados: Através do instrumento avaliativo observou-se que dentro de 10 variáveis avaliadas sobre o ensino semipresencial na ASCES-UNITA, obteve-se 5 destas variáveis com grau satisfatório e as outras 5 com grau insatisfatório. Conclusão: Conclui-se que o ensino semipresencial é avaliado como um importante instrumento para o crescimento acadêmico, pois proporciona ao aluno o incentivo a busca dos seus conhecimentos. Nesta pesquisa apesar das dificuldades iniciais e algumas resistências, é possível construir e explanar os fundamentos a partir deste método, podendo assim contribuir positivamente no processo de ensino aprendizagem do enfermeiro em formação.

Palavras-chave: Educação em enfermagem, Modelos educacionais, Estudantes.

\begin{abstract}
Objective: To evaluate or semipresencial ensino no Bacharelado course in Enfermagem over two students. Methods: This is a cross-sectional, descriptive and explanatory study, with a quantitative approach with 134 students from the Centro Universitário Tabosa de Almeida (ASCES-UNITA), in a city in Pernambuco. The data were analyzed using descriptive statistics with central trend analysis, in this case the mean and standard deviation. The research project was approved by the Ethics Committee.Results: Through the evaluative instrument, it was observed that within 10 variables evaluated on semi-presential education at ASCES-UNITA, 5 of these variables were obtained with satisfactory degree and the other 5 with unsatisfactory degree. Conclusion: It is concluded that semi-presential teaching is evaluated as an important instrument for academic growth, as it provides students with the incentive to search for their knowledge. In this research, despite the initial difficulties and some resistance, it is possible to build and explain the fundamentals from this method, thus being able to positively contribute to the teaching process of the nurse in training.
\end{abstract}

Key words: Nursing education, Educational models, Students.

1 Centro Universitário Tabosa de Almeida (ASCES-UNITA), Caruaru - PE. *E-mail: smariaana30@gmail.com

2 Pesquisadora do Instituto de Estudos Avançados (IEA) - ASCES UNITA, Caruaru-PE. 


\section{RESUMEN}

Objetivo: Evaluar la enseñanza semipresencial en el curso de Licenciatura en Enfermería desde la perspectiva de los alumnos. Métodos: Este es un estudio transversal, descriptivo y explicativo, con un enfoque cuantitativo con 134 estudiantes del Centro Universitario Tabosa de Almeida (ASCES-UNITA), en una ciudad de Pernambuco. Los datos se analizaron mediante estadísticas descriptivas con análisis de tendencia central, en este caso la media y la desviación estándar. El proyecto de investigación fue aprobado por el Comité de Ética. Resultados: A través del instrumento evaluativo se observó que dentro de 10 variables evaluadas en la enseñanza semipresencial en ASCES-UNITA, 5 de estas variables se obtuvieron con grado satisfactorio y las otras 5 con grado insatisfactorio. Conclusión: Se concluye que la enseñanza semipresencial se evalúa como un instrumento importante para el crecimiento académico, ya que proporciona a los estudiantes el incentivo para buscar su conocimiento. En esta investigación, a pesar de las dificultades iniciales y cierta resistencia, es posible construir y explicar los fundamentos de este método, pudiendo así contribuir positivamente al proceso de enseñanza de la enfermera en el entrenamiento.

Palabras clave: Educación en enfermería, Modelos educativos, Estudiantes.

\section{INTRODUÇÃO}

Diante de atuais exigências sociais e profissionais, evidencia-se a necessidade de transformações e melhorias na formação acadêmica de um profissional de saúde, pois o crescimento dos espaços de trabalho, demandam requerer profissionais capacitados, pautados no conhecimento e no desenvolvimento de habilidades e competências para lidar com tomadas de decisões no cotidiano de trabalho. Para lidar com esta necessidade atual, métodos inovadores de ensino-aprendizagem tornam-se uma ótima ferramenta para aperfeiçoar a construção do conhecimento teórico-prático dos profissionais de saúde, permitindo o desenvolvimento de sua postura crítico-reflexiva (SILVA NA, et al., 2015; GODOY SCB, et al., 2014).

O sistema de ensino misto, conhecido por blended learning (ensino híbrido) já é realizado no Brasil desde a década de 70 do século passado, esse conceito já estava presente, por exemplo, nos projetos de educação à distância por radiodifusão. Até o início da década de 80 o ensino híbrido era realizado em material impresso produzido e enviado aos alunos (VALENTE JA, 2014).

Com o avanço das tecnologias foram criadas diversas modalidades de ensino a distância, inclusive o blended learning, que combina atividades presenciais e atividades educacionais à distância, realizadas por meio das tecnologias digitais de informação e comunicação. A expansão dessa modalidade só iria experimentar um crescimento significativo com a criação e disseminação de novas tecnologias educacionais on-line, gerenciadas a partir de um único sistema, os chamados learning management system, ou LMS, traduzido para o português, Sistema de Gestão da Aprendizagem (RODRIGUES LA, 2010).

O ensino semipresencial pode ser oferecido aos discentes até $20 \%$ da carga horária total de um curso. Esta modalidade foi regulamentada pelo Ministério de Estado da Educação, pela Lei oㅜ 9.394, de 20 de dezembro de 1996, e pelo Decreto de № 2.494, de 10 de fevereiro de 1998, no qual a Portaria de № 4.059, de 10 de dezembro de 2004 (DOU de 13/12/2004, Seção 1, p. 34), descreve o ensino semipresencial como:

"Art. $1^{\circ}, \S 1^{\circ}$ : Para fins desta Portaria, caracteriza-se a modalidade semipresencial como quaisquer atividades didáticas, módulos ou unidades de ensino-aprendizagem centrados na autoaprendizagem e com a mediação de recursos didáticos organizados em diferentes suportes de informação que utilizem tecnologias de comunicação remota. " (BRASIL, 2004).

Existe a educação presencial, semipresencial e educação à distância. A presencial é caracterizada por docentes e discentes estarem no mesmo local físico. Já o semipresencial é quando as aulas acontecem uma parte em sala de aula e outra parte a distância por meios de tecnologias e pôr fim a educação a distância que pode ter ou não momentos presenciais, mas a maioria do tempo este tipo de educação acontece com professores e alunos separados de um local físico, o ensino acontece por meio de tecnologias de comunicação (MORAN JM, 1994). 
O ensino semipresencial no Centro Universitário Tabosa de Almeida (ASCES/UNITA), cujo curso de bacharelado em Enfermagem é o pioneiro na instituição, está sendo utilizado para promover uma interação que possibilita práticas mais fáceis de concretizar em ambientes virtuais do que na sala de aula, como a realização de trabalhos colaborativos, portfólios, atividades em rede e construção coletiva de conhecimento. Acredita-se que este ensino permita a metodologia ativa, despertando no discente um olhar crítico e uma autonomia através de sua própria aprendizagem (SOUSA VJ e LOPES V, 2016; PRADO C, et al., 2012).

E a partir disso o ensino semipresencial contribui para a formação dos estudantes, porém há a necessidade de identificação dos desafios, das possibilidades, dos benefícios e dificuldades descritas pelos mesmos enquanto participantes de Unidades Temáticas de Ensino Semipresencial nesta instituição. Portanto, este estudo tem como objetivo avaliar o ensino semipresencial no curso de Bacharelado em Enfermagem sob a ótica dos discentes.

\section{MÉTODOS}

O estudo teve uma abordagem quantitativa e trata-se de uma pesquisa explicativa, descritiva e transversal realizada no Centro Universitário Tabosa de Almeida (ASCES-UNITA), na cidade de Caruaru PE. A população do estudo foi composta por todos os alunos que passaram pela Unidade Temática 10 do 3ํㅡódulo do Curso de Enfermagem, na Instituição de Ensino Superior (IES).

A amostra dos dados foi definida por meio de conveniência, composta por 134 alunos, que é a população total de discentes do curso de bacharelado em Enfermagem da referida IES, que vivenciaram a experiência do ensino semipresencial do $4^{\circ}$ ao $8^{\circ}$ Módulo, e os mesmos concordaram em participar do estudo através do termo de consentimento livre e esclarecido (TCLE). Foi determinado como critérios de inclusão: alunos matriculados na IES e alunos que tenham passado pela unidade temática de ensino semipresencial (que ocorre a partir do $3^{\circ}$ Módulo) e como critérios de exclusão: alunos que estivessem cursando a Unidade Temática 10 e discentes da Matriz Curricular do ano de 2011.

A coleta de dados foi realizada através de um questionário avaliativo, com 10 perguntas, sendo todas objetivas. O mesmo foi testado e modificado de acordo com as contribuições dadas. O questionário passou por um teste piloto enviado por e-mail para algumas ex-alunas da instituição que passaram pela unidade temática 10 no $3^{\circ}$ módulo e na devolução do questionário tinham algumas contribuições, dentre elas, a clareza na linguagem, visto que as perguntas estavam um pouco complexas e dúbias.

Os dados foram coletados do dia 24 ao dia 30 de Novembro de 2017, nos turnos da manhã e noite, nas salas de aula do curso de graduação em Enfermagem, onde os discentes preencheram o questionário no horário de intervalo, para não os prejudicar em sala de aula e em um tempo aproximado de 3 minutos foi possível responder o questionário.

Para a análise dos dados, o questionário conseguiu avaliar o objetivo do estudo, que teve as suas 10 variáveis analisadas, por meio de uma escala nominal, realizada por estatística descritiva com análise de tendência central, neste caso a média e o desvio padrão.

O instrumento de coleta de dados apresentava 10 questões com 4 alternativas numeradas, quanto mais próximo do número 4 , maior a satisfação do estudante, logo quanto mais longe, menor sua satisfação. Sendo assim, após a coleta dos dados, medidas de cálculo estatístico foram realizadas com o auxílio do Microsoft Excel para análise e apresentação dos dados. O estudo segue os termos da Resolução 466/12 que descreve as diretrizes e as normas regulamentadoras de pesquisa envolvendo seres humanos, tendo sido aprovado pelo Comitê de Ética em Pesquisa da ASCES/UNITA sob o oㅡ do Parecer: 2.393.686 e o ํㅜ do CAAE: 67862217.3.0000.5203.

\section{RESULTADOS}

Para avaliar o ensino semipresencial do Centro Universitário Tabosa de Almeida (ASCES/UNITA) em Caruaru-PE, 134 alunos responderam um questionário, que serviu como instrumento avaliativo, que visou buscar evidências que comprovassem a eficiência da metodologia ativa e também identificasse as 
fragilidades e as potencialidades de forma que agregasse qualidade a unidade temática de ensino semipresencial sob à ótica dos discentes. Os resultados deste estudo apresentam-se na Tabela 1. As variáveis que obtiveram o valor aproximadamente a 4, foram avaliadas como grau satisfatório, já as variáveis que obtiveram o valor $<3$, foram avaliadas como grau insatisfatório. A Tabela 1 apresenta como os discentes de Enfermagem consideram a influência deste método de ensino-aprendizagem na sua jornada acadêmica, como forma para melhoria da construção do seu conhecimento e busca pelas informações cientificas, que molda o aluno para ser um profissional dinâmico, utilizando de estratégias para seu crescimento profissional e habilidades para se trabalhar em equipe. A partir desta reflexão sobre o que 0 método de ensino é capaz de permitir ao discente, foi possível realizar a avaliação do ensino semipresencial no curso de Bacharelado em Enfermagem.

Tabela 1 - Avaliação dos discentes sobre o ensino semipresencial no curso de Bacharelado em Enfermagem. Caruaru, 2017.

\begin{tabular}{c|c|c|c|c|c}
\hline \multirow{2}{*}{ Variáveis } & \multicolumn{5}{|c}{ Média e desvio padrão } \\
\cline { 2 - 6 } & $\mathbf{4 M}$ & $\mathbf{5 M}$ & $\mathbf{6 M}$ & $\mathbf{7 M}$ & $\mathbf{8 M}$ \\
\hline $\begin{array}{c}\text { Construção do } \\
\text { conhecimento }\end{array}$ & $3,12 \pm 0,33$ & $3,32 \pm 0,48$ & $3,15 \pm 0,46$ & $3,23 \pm 0,43$ & $3,28 \pm 0,53$ \\
Estímulo pelo método de & $3,00 \pm 0,50$ & $3,55 \pm 0,61$ & $2,80 \pm 0,83$ & $2,95 \pm 0,49$ & $2,97 \pm 0,63$ \\
$\quad$ ensino & & & & & \\
Liberdade de opinião & $3,88 \pm 0,33$ & $3,52 \pm 0,77$ & $3,62 \pm 0,64$ & $3,56 \pm 0,73$ & $3,69 \pm 0,60$ \\
$\quad \begin{array}{l}\text { Incentivo à leitura } \\
\text { Convivência entre }\end{array}$ & $3,94 \pm 0,24$ & $3,79 \pm 0,42$ & $3,55 \pm 0,64$ & $3,58 \pm 0,54$ & $3,66 \pm 0,55$ \\
$\quad$ estudantes & $3,25 \pm 0,44$ & $3,47 \pm 0,51$ & $3,12 \pm 0,52$ & $3,30 \pm 0,51$ & $3,45 \pm 0,51$ \\
$\quad \begin{array}{l}\text { Convivência entre } \\
\text { estudante-tutor }\end{array}$ & $3,59 \pm 0,50$ & $3,26 \pm 0,65$ & $3,38 \pm 0,57$ & $3,49 \pm 0,55$ & $3,41 \pm 0,73$ \\
Autonomia de estudo & $3,24 \pm 0,44$ & $3,16 \pm 0,50$ & $3,00 \pm 0,69$ & $3,07 \pm 0,70$ & $3,28 \pm 0,53$ \\
Suporte técnico da IES & $2,24 \pm 0,66$ & $2,84 \pm 0,69$ & $2,50 \pm 1,02$ & $2,12 \pm 0,88$ & $2,24 \pm 1,09$ \\
Ambientes virtuais & $3,24 \pm 0,66$ & $2,58 \pm 0,84$ & $2,27 \pm 0,87$ & $2,54 \pm 0,74$ & $3,03 \pm 0,73$ \\
$\quad$ selecionados & & & & & \\
Comparação com o & $2,59 \pm 0,87$ & $3,11 \pm 0,94$ & $2,04 \pm 0,92$ & $2,65 \pm 0,95$ & $2,51 \pm 0,83$ \\
ensino tradicional & & & & & \\
\hline
\end{tabular}

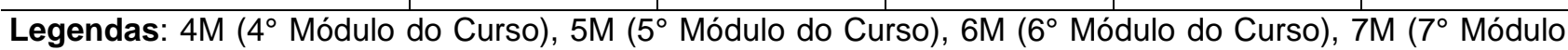
do Curso), 8M ( $8^{\circ}$ Módulo do Curso). Fonte: Silva MAL, et al., 2020.

\section{DISCUSSÃO}

No Centro Universitário Tabosa de Almeida (ASCES-UNITA), a implementação do modelo semipresencial foi pioneira no curso de graduação em Enfermagem, no município de Caruaru - PE, tendo início no dia 24 de fevereiro de 2014, este tipo de ensino híbrido está contido na carga horária obrigatória do curso. Tendo encetamento no $3^{\circ}$ módulo, na Unidade Temática (UT) 10 em que a modalidade semipresencial é trabalhada com eixo temático da Atenção Primária em Saúde (APS), trazendo aos alunos situações reais dos serviços de saúde da APS, voltados a gestão e a assistência.

Como pontos positivos, os alunos destacaram que a disciplina do semipresencial estimula a construção do conhecimento onde o discente deve tomar cuidado com a qualidade dos materiais escolhidos para estudo, visto que no momento presencial foi utilizado a Aprendizagem Baseada em Problemas (ABP). A literatura afirma que este é um método de aprendizagem inovador, onde estabelece ao discente um planejamento com suas atividades que irão ajudar a apreender todo o conhecimento transmitido na tutoria, ajudando assim a buscar ou melhorar sua própria autonomia (SOUSA SC e DOURADO L, 2015).

Um estudo de natureza quantitativa, objetivou comparar a eficácia do aprendizado semipresencial e de um folheto educacional sobre a retenção de atualizações de diabetes por enfermeiros. $O$ método semipresencial foi identificado como o mais eficaz do que o folheto para aprimorar o aprendizado e a 
retenção de conhecimento dos enfermeiros. Foi considerado pelo estudo como um método mais adequado para a atualização dos enfermeiros quanto a temática escolhida, pois forneceu interações apropriadas e ambientes virtuais atraentes que estimulou e motivou os alunos a atualizar seus conhecimentos (BADIEI M, et al., 2016).

Outro ponto positivo encontrado nesse estudo, foi a liberdade de opinião, onde os entrevistados demonstraram ter essa liberdade sobre seus conhecimentos utilizando nessa modalidade de ensinoaprendizagem. Entende-se que ter esta liberdade é primordial, visto que a interação se faz presente no ensino semipresencial, afinal a mesma permite que a construção do conhecimento venha pelo diálogo, pois a troca constante de saberes junto aos colegas e professores, faz com que os mesmos superem a distância física e tenham em vista o compromisso assumido com sua autoaprendizagem (BRETTAS LA, et al., 2005).

Percebe-se neste estudo que o incentivo à leitura teve uma boa aceitação, afinal a realização das atividades vai de acordo com a necessidade e característica de cada aluno, então é necessário estabelecer horários e ter um local apropriado para dar início ao cumprimento das atividades. A literatura afirma que manter a prática da leitura no ensino semipresencial significa não apenas contribuir para inseri-los em práticas sociais como: maneiras de falar, ouvir, ler, agir e interagir, mas também os privilegiam a ter uma melhora na prática gramatical, portanto é fundamental ter um suporte técnico e pedagógico para conseguirem ter uma interação permanente com seus colegas de tutoria para o esclarecimento de dúvidas e ter incentivo para dar continuidade aos estudos (PINTO CM e FICHER A, 2014).

Percebeu-se em nosso estudo, a convivência entre estudantes, os entrevistados também avaliaram satisfatoriamente, visto que o tutor produz dinâmicas que envolvem a participação ativa dos alunos provocando neles um interesse, uma dedicação e disponibilidade para realizar as tarefas propostas na tutoria. Esta convivência facilita a troca de saberes e melhora o aprendizado individual e coletivo, favorecendo a compreensão de que o trabalho em equipe faz parte do novo contexto acadêmico e evidenciam melhor o debate ampliando a visão teórico-prática de cada um (FRISON LMB, 2012).

A convivência entre estudante-tutor foi apontada com boa pontuação, uma vez que a presença de um docente dentro do ensino semipresencial consegue desenvolver o papel de mediador, que orienta e interage através dos encontros presenciais e virtuais. Estudos ressaltam que o mediador deve estar constantemente orientando, dirigindo e supervisionando o processo de ensino-aprendizagem e entender que sua capacidade para trabalhar em tutoria, deve atender às necessidades dos alunos e respeitar as limitações deles também (MEHLECKE Q, et al., 2005).

Ao se tratar de convivência, um estudo que buscou compreender o impacto do ensino semipresencial na prática de profissionais de saúde, resultou em um impacto positivo nos aspectos relacionadas ao processo de cuidado, de trabalho em equipe e de organização e gestão do trabalho na Estratégia de Saúde da Família (ESF), pois a especialização nessa modalidade, permitiu que os alunos melhorassem sua prática cotidiana em relação ao estabelecimento de vínculo com os demais profissionais e os usuários, o que para eles foi considerado essencial para um processo de cuidado ampliado e inovador (MARIN MJS, et al., 2017).

Têm-se também como ponto positivo no ensino semipresencial, a autonomia de estudo, onde o discente durante os momentos de tutoria começa a desenvolver a sua autonomia diante o momento de aprendizagem, afinal contribuir para a formação dos colegas de turma é sempre bom, e é um modo também de mostrar que é comprometido com o estudo, além de ser responsável e ter organização com seu tempo na busca contínua do aprendizado. A literatura afirma que o aluno após assumir sua autonomia diante do grupo ele passa a criar uma nova rede de relacionamentos que vai favorecer 0 desenvolvimento cognitivo de todo o grupo (BRETTAS LA, et al, 2005; SOUZA S, et al., 2016).

Já em relação aos pontos negativos do ensino semipresencial no Centro Tabosa de Almeida (ASCES/UNITA), como exibido na Tabela 1, a variável sobre o 'Suporte técnico da IES' teve grau insatisfatório diante de todos os módulos entrevistados, o uso de Tecnologias de Informação e Comunicação (TIC) são as ferramentas fundamentais no ensino semipresencial, afinal elas contribuem para o favorecimento da autonomia dos alunos e acabam criando novos caminhos de comunicação entre o aluno 
e o tutor. Estudo afirma que as TICs fazem parte do processo de ensinar e aprender à distância, porque a dificuldade diante do suporte técnico dentro da IES vem através do acesso ruim à internet e da pouca habilidade no uso das ferramentas básicas de informática para conseguir a realização das tarefas no Ambiente Virtual de Aprendizagem (AVA) (OLIVEIRA C, et al., 2015).

Observou-se que 4 módulos deram como grau insatisfatório e apenas o $5 \mathrm{M}$ classificou como grau satisfatório a variável de 'Comparação com o ensino tradicional', percebe-se que devido a educação presencial ser caracterizada por docentes e discentes estarem no mesmo local físico e com atividades que são mecanismos complementares de estudo e reforço, fazendo com que este tipo de ensino não possua o chamado tutor que é o intermediador do processo ensino-aprendizagem, fazendo com que a educação presencial fique mais focada no professor, ou seja, o discente tem que se empenhar mais para obter 0 aprendizado, por isso o mesmo acaba tendo mais aceitação do que o ensino semipresencial (MARCHI ACB, et al., 2008).

Em contrapartida, um estudo que buscou avaliar a contribuição de um programa de educação permanente semipresencial no conhecimento de enfermeiros sobre estomias intestinais de eliminação, percebeu que a modalidade semipresencial foi de grande valia para qualificação profissional, à modalidade tradicional. Identificou-se melhoria no conhecimento teórico-prático dos enfermeiros em questões relacionadas ao cuidado de Enfermagem no perioperatório das cirurgias geradoras de estomias intestinais de eliminação, em particular no contexto hospitalar, pois é método foi flexível e adequou-se às características exigidas pela profissão, após a realização do programa de educação permanente semipresencial (MONTEIRO AKC, et al., 2019).

Um estudo explanou que ensino semipresencial é quando as aulas acontecem uma parte em sala de aula e outra parte a distância por meios de tecnologias, favorecendo com que este ensino seja um recurso tecnológico para realização de desempenhos complementares, tendo auxílio das tecnologias que complementam os conteúdos discutidos de momento presencial. Nesta nova modalidade de ensino o docente busca inovação, aceitação e capacitação para atuar por meio dos recursos técnico educacionais, passando a ser um facilitador do discente (JUNIOR ER e FERNANDES FJ, 2014).

Já nas variáveis de estímulo pelo método de ensino e ambientes virtuais selecionados os módulos ficaram divididos entre as opiniões, mas mesmo assim o grau insatisfatório prevalece, mas o estímulo pelo método de ensino faz com que a tutoria seja entendida como uma articulação didática. Este método foi considerado em estudo, como capaz de compreender e utilizar um conjunto de ações educativas que contribuem para desenvolvimento e potencialização das habilidades básicas dos alunos, não esquecendo que o tutor está sempre ali facilitando a obtenção do crescimento intelectual e da autonomia (SCHLOSSER $\mathrm{RL}, 2010)$.

E por fim, os ambientes virtuais selecionados tiveram também uma prevalência de maior grau insatisfatório, devido ao decorrer da tutoria que o estudante passa por momentos que tem a presença do AVA, que é caracterizado como o principal espaço social de interações entre estudantes e tutor, onde todos estarão envolvidos e poderão dialogar, trocar ideias e compartilhar conhecimentos.

A literatura afirma que neste ambiente são traçadas estratégias e intervenções que levam os estudantes a construir seu próprio conhecimento. Lembrando que ele apresenta ferramentas que potencializam os processos de interação, colaboração e de cooperação (MARCHI ACB, et al., 2008). No Centro Universitário Tabosa de Almeida o AVA ocorre de modo assíncrono, na Plataforma Educacional Google Classroom, em formato de fórum, fazendo com que os alunos busquem conhecimentos relativos às "Questões de Aprendizagem - QA" para si e que socializam com o seu grupo de tutoria.

Já no momento do chat ele ocorre de modo síncrono, por meio do aplicativo Hangouts do Google utilizando exclusivamente o gmail institucional de cada aluno, fazendo com que os estudantes rediscutam os problemas a partir dos novos conhecimentos adquiridos com seus estudos durante todos os momentos da tutoria, oportunizando o discente a ter a sua própria construção e até mesmo instigando a reconstrução de alguns conceitos para melhorar as suas concepções diante do seu empoderamento (SOUSA VJ e LOPES V, 2016). 
Tendo em vista os pontos negativos percebe-se a necessidade um estudo qualitativo, como forma de aprofundar o conhecimento sobre as dificuldades e facilidades vivenciadas pelos estudantes, para colaborar no aprimoramento da metodologia proposta.

\section{CONCLUSÃO}

Desta forma, os alunos do $4^{\circ}$ ao $8^{\circ}$ módulo do curso de Enfermagem no Centro Universitário Tabosa de Almeida (ASCES-UNITA) da cidade de Caruaru-PE, avaliam o ensino semipresencial como algo enriquecedor, que rompe paradigmas de ensino e torna-se um importante instrumento utilizado pela IES. Observasse que nesta pesquisa os alunos apontaram muitos pontos positivos em relação à modalidade semipresencial, apesar das dificuldades iniciais e algumas resistências, dá para construir e explanar os fundamentos diante desta metodologia, podendo assim contribuir positivamente no processo de ensino aprendizagem. Por conseguinte, é evidente que para o sucesso dessa modalidade são necessários o suporte da IES e também do professor, muito mais do que os discentes. A autonomia que este ensino permite faz com que os discentes consigam se auto gerenciar na aprendizagem. Para fins deste estudo, é necessário que a IES tenha uma melhora na rede de internet para proporcionar uma experiência adequada aos alunos que ainda vivenciarão a Unidade Temática 10.

\section{REFERÊNCIAS}

1. BADIEI M, et al. Comparing nurses' knowledge retention following electronic continuous education and educational booklet: a controlled trial study. Rev Med J Islam Repub Iran, 2016; 30(364): 1-7.

2. 2.BRASIL, Ministério da Educação. Portaria n. -4.059 , de 10 de dezembro de 2004. Aprova e regulamenta modalidade semipresencial de ensino. Brasília; 2004.

3. BRETTAS LA, et al. Ensino a Distância: Novos conceitos pedagógicos são necessários ou os conceitos que já existem são suficientes? Novas Tecnologias na Educação, 2005; 3(1): 1-13.

4. FRISON LMB. Tutoria entre estudantes: uma proposta de trabalho que prioriza a aprendizagem. Revista Portuguesa de Educação, 2012; 25(2): 217-240.

5. GODOY SCB, et al. Avaliação da capacitação dos enfermeiros em unidades básicas de saúde por meio da telenfermagem. Esc Anna Nery Rev Enferm, 2014; 18 (1): 148-155.

6. JUNIOR ER, FERNANDES FJ. Proposta de inclusão de carga horária semipresencial em cursos superiores presenciais. Avaliação (Campinas), 2014; 19(1), 179-192.

7. MARCHI ACB, ARAÚJO DD, ISTREIT IR. Modalidade semipresencial de ensino: alguns resultados da implantação em disciplinas de graduação da UPF. Renole, 2008; 6(2): 1-10.

8. PINTO CM e FISCHER A. O discurso sobre leitura e escrita de um estudante EaD em formação. Calidoscópio, $2014 ; 12(1): 15-23$.

9. MARIN MJS, et al. Formação na Modalidade a Distância pela Universidade Aberta do SUS: Estudo Qualitativo sobre o Impacto do Curso na Prática Profissional. Rev Bras Educação Médica, 2017; 41(2): 201-209.

10. MEHLECKE Q, PEREIRA A, TAROUCO L. Estratégias de interação entre tutor e estudantes em educação a distância. Lume, 2005; 3(1): 1-10.

11. MONTEIRO AKC, et al. Contribuição de educação permanente semipresencial no conhecimento de enfermeiros sobre estomias intestinais de eliminação. Rev Min Enferm, $2019 ;(23)$ : e-1177.

12. MORAN J. O que é educação à distância. SENAI; Rio de Janeiro, 1994. 5(1): 1-3.

13. OLIVEIRA C, MOURA SP, SOUSA ER. Tic's na educação: A utilização das tecnologias da informação e comunicação na aprendizagem do aluno. Pedagogia em Ação, 2015; 7(1): 75-95.

14. PRADO C, et al. Ambiente virtual de aprendizagem no ensino de Enfermagem: relato de experiência. Ver Bras Enferm, 2012; 65(5): 862-866.

15. RODRIGUES LA. Uma nova proposta para o conceito de Blended Learning. Interfaces da Educ. Paranaíba, 2010; 1(3): 5-22.

16. SCHLOSSER RL. A atuação dos tutores nos cursos de educação a distância. Digital da CVA - Ricesu, 2010; 6(22): 1-6.

17. SILVA NA, et al. Limites e possibilidades do ensino a distancia (EaD) na educacao permanente em saude: revisão integrativa. Ver Ciênc Saúde Colet, 2015; 20 (4): 1099-1107.

18. SOUSA SC, DOURADO L. Aprendizagem baseada em problemas (ABP): Um método de aprendizagem inovador para o ensino educativo. Holos, 2015; 5(1): 182-200.

19. SOUSA VJ, LOPES V. Ensino de enfermagem em ambientes virtuais de aprendizagem com metodologia ABP. Repositório Asces, 2016; 1-6.

20. SOUZA S, et al. Educação a distância na ótica discente. Rev Educ Pesqui, 2016; 42(1): 99-113.

21. VALENTE JA. Blended learning e as mudanças no ensino superior: a proposta da sala de aula invertida. Educar em Revista, 2014; 4(1):79-97. 